\title{
In situ concentration of semi-volatile aerosol using water-condensation technology
}

\author{
Andrey Khlystov ${ }^{\mathrm{a}, *}$, Qi Zhang ${ }^{\mathrm{b}}$, Jose L. Jimenez ${ }^{\mathrm{b}}$, Charlie Stanier ${ }^{\mathrm{c}}$, Spyros N. Pandis ${ }^{\mathrm{c}}$, \\ Manjula R. Canagaratna ${ }^{\mathrm{d}}$, Philip Fine ${ }^{\mathrm{e}}$, Chandan Misra ${ }^{\mathrm{e}}$, Constantinos Sioutas ${ }^{\mathrm{e}}$ \\ a Department of Civil and Environmental Engineering, Duke University, Box 90287, Durham, NC 27708, USA \\ ${ }^{\mathrm{b}}$ Department of Chemistry and CIRES, University of Colorado, Boulder, CO 80309, USA \\ ${ }^{\mathrm{c}}$ Department of Chemical Engineering, Carnegie Mellon University, Pittsburgh, PA 15213, USA \\ ${ }^{\mathrm{d}}$ Center for Aerosol and Cloud Chemistry, Aerodyne Research Inc., Billerica, MA 01821, USA \\ ${ }^{\mathrm{e}}$ Department of Civil and Environmental Engineering, University of Southern California, Los Angeles, CA 90089, USA
}

Received 12 July 2004; received in revised form 6 November 2004; accepted 8 November 2004

\begin{abstract}
The effect of concentrating semi-volatile aerosols using a water-condensation technology was investigated using the Versatile Aerosol Concentration Enrichment System (VACES) and the Aerodyne Aerosol Mass Spectrometer (AMS) during measurements of ambient aerosol in Pittsburgh, PA. It was found that the shape of the sulfate mass-weighed size distribution was approximately preserved during passage through the concentrator for all the experiments performed, with a mass enhancement factor of about 10-20 depending on the experiment. The size distributions of organics, ammonium and nitrate were preserved on a relatively clean day (sulfate concentration around $7 \mu \mathrm{g} / \mathrm{m}^{3}$ ), while during more polluted conditions the concentration of these compounds, especially nitrate, was increased at small sizes after passage through the concentrator. The amount of the extra material, however, is rather small in these experiments: between $2.4 \%$ and $7.5 \%$ of the final concentrated PM mass is due to "artifact" condensation. An analysis of thermodynamic processes in the concentrator indicates that the extra particle material detected can be explained by redistribution of gas-phase material to the aerosol phase in the concentrator. The analysis shows that the condensation of extra material is expected to be larger for water-soluble semi-volatile material, such as nitrate, which agrees with the observations. The analysis also shows that artifact formation of nitrate will be more pronounced in ammonia-limited conditions and virtually undetectable in ammonia-rich conditions.
\end{abstract}

(C) 2004 Elsevier Ltd. All rights reserved.

Keywords: Particle concentrator; AMS; Semi-volatile aerosol; Nitrate; Organic aerosol

\footnotetext{
* Corresponding author. Tel.: +1919660 5209; fax: +1919660 5219.

E-mail address: andrey@duke.edu (A. Khlystov).
} 


\section{Introduction}

Several epidemiological studies have proposed that increased concentrations of ambient particulate matter (PM) are responsible for adverse human health effects (Peters, Dockery, Heinrich, \& Wichmann, 1997; Pope, Dockery, \& Schwartz, 1995; Thurston, Ito, Hayes, Bates, \& Lippmann, 1994). However, the exact mechanism by which inhaled particles affects human health remains a subject of much research and debate. In order to facilitate studies of the adverse effects of PM on health, particle concentrators have been developed (Kim et al., 2001a; Kim, Jaques, Chang, Froines, \& Sioutas, 2001b; Sioutas, Kim, \& Chang, 1999). These devices allow exposure of human or animal subjects to controlled elevated concentrations of ambient PM and, thus, are extremely useful research tools. In addition to their application in the health research, particle concentrators can also be used to reach lower detection limits with instruments measuring aerosol concentration and/or composition, as well as to reduce the effect of gaseous artifacts on aerosol measurements (Eatough, Pang, \& Eatough, 1999).

The heart of a particle concentrator is a virtual impactor (Willeke \& Baron, 1993). Particles larger than a certain cut-off size, which depends on the impactor design, are concentrated in the minor flow of the impactor, with the concentration factor being approximately the ratio of the total sampling flow rate of the impactor to the flow rate of its minor flow. Concentration factors of up to 40 can typically be achieved. Cut-off sizes of less than about $100 \mathrm{~nm}$, however, require a very high pressure drop across the impactor and are therefore not practical. In addition, high pressure drops may cause evaporative losses of semi-volatile aerosol during the concentration process, since the partial pressure of the species in the gas phase has been significantly decreased. For these reasons most concentrators enhance concentration of fine aerosol, while concentration of ultra-fine particles (smaller than $100 \mathrm{~nm}$ ) remains unchanged. Since ultra-fine particles are also proposed as one of the causative agents in the adverse health effects (Peters et al., 1997), the Versatile Aerosol Concentration Enrichment System (VACES) (Kim et al., 2001a,b) has been developed which uses water-condensation technology to concentrate ultra-fine particles.

The operation principle of the VACES is similar to that of other particle concentrators, but differs in that particles are grown by water condensation prior to passage through the virtual impactor. The instrument creates a super-saturation of water vapor by passing the air first through a warm saturator and then through a cold condenser. The super-saturation causes water condensation onto the particles, which as a result grow in size and can be concentrated without the need of a high pressure drop. The VACES was demonstrated to be capable of enriching the concentration of particles in the range of $0.01-10 \mu \mathrm{m}$ by a factor of up to 40 (Kim et al., 2001a,b). Its small size and modular design makes it well suited for studies using mobile exposure platforms. In addition, the VACES can be readily adapted to accommodate higher output flow rates, which are desirable in conducting human exposure studies. The portability and the high concentration enhancement factors of these particle concentrators make them also very attractive for measurements of an aerosol component which is below or close to the detection limit of the available measurement techniques for the available time. Application of the VACES to increase the aerosol concentration in front of the instruments during sampling may decrease the detection limit of the instrument by up to a factor of 40 .

Water condensation and the changes in temperature of the air during the passage through the concentrator raise concerns of possible changes in gas/aerosol partitioning, i.e. sampling artifacts. However, a study by Zhao et al. (2004) found no detectable sampling artifacts for the VACES concentrator. Here we describe our observations during field measurements in which the VACES concentrator was coupled to an Aerodyne Aerosol Mass Spectrometer (AMS) (Jayne et al., 2000; Jimenez et al., 2003). The 
measurements were conducted during the Pittsburgh Air Quality Study at the central monitoring site in Pittsburgh, PA, during September 2002. The main aim of this study was to determine the applicability of the VACES-AMS combination to measurements of aerosol chemical composition during nucleation events. Because of the different nature of the problem, namely the very low aerosol concentrations during these events, attention has been given to small changes in aerosol composition (of the order of 5\% of the concentrated mass) that were not relevant to the previous characterization studies of the VACES (Geller et al., 2002; Kim et al., 2001b; Misra, Fine, Singh, \& Sioutas, 2004).

\section{Methods}

\subsection{VACES}

The VACES concentrator is described in detail elsewhere (Kim et al., 2001a,b). The concentrator used in our studies consisted of a single sampling line operating at an intake flow rate of 112 1/min (LPM), which was checked before and after experiments using a gas flow meter. In the VACES the air stream is saturated with water vapor in a humidifier, which is a 101 aluminum vessel half-filled with water and maintained at $38^{\circ} \mathrm{C}$. The air stream is directed at and passes above the water surface. The residence time in the humidifier is about $3 \mathrm{~s}$. Doubly de-mineralized water $(18.1 \mathrm{M} \Omega / \mathrm{cm})$ was used in the humidifier. By passing through the humidifier the air is saturated with water vapor and warmed up to about $30{ }^{\circ} \mathrm{C}$ ( $\mathrm{Kim}$ et al., 2001a). After leaving the humidifier the air enters a condenser, a stainless steel pipe that is surrounded by a mixture of water and rock-salt, which was regularly stirred. The temperature of the cooling mixture in the condenser was $-8 \pm 0.5^{\circ} \mathrm{C}$ and was checked using a digital thermometer. The actual temperature of the air stream in the condenser is $20-21^{\circ} \mathrm{C}$ (Kim et al., 2001a). Due to the sharp drop in temperature (about $10^{\circ} \mathrm{C}$ ) the air in the condenser becomes strongly supersaturated. The supersaturation causes water vapor to condense onto particles as small as $20 \mathrm{~nm}$ in size, which rapidly grow to $2.5-3 \mu \mathrm{m}$ water droplets. These droplets are subsequently concentrated by a virtual impactor, exiting via its minor air flow. After leaving the virtual impactor, the droplets were dried with a silica-gel diffusion dryer, thus bringing the concentrated aerosol particles to their original size. The ideal concentration factor is equal to the ratio of the inlet flow to the minor flow (5 LPM in this study) of the virtual impactor, i.e. in this study it was 22. The minor flow was regularly checked with a Gillibrator (Sensidyne, Inc. Clearwater, Florida) and constantly monitored by observing the pressure drop across the virtual impactor.

\subsection{Aerodyne AMS}

The Aerodyne AMS measures size-resolved mass distributions and total mass loadings of non-refractory chemical species in/on submicron particles. This instrument and the associated quantification procedures have been described in detail in other publications (Alfarra et al., 2004; Allan et al., 2004; Jayne et al., 2000; Jimenez et al., 2003), and only a brief summary will be given here. The results from the deployment of this instrument in Pittsburgh are described in Zhang, Canagaratna, Jayne, Worsnop, and Jimenez (2004a) and Zhang et al. (2004b). The AMS uses an aerodynamic lens to focus the particles into a narrow beam, a roughened cartridge heater to vaporize them under high vacuum, and an electron impact ionizer coupled to a quadrupole mass spectrometer to analyze the vaporized molecules. Particle size is measured via particle time-of-flight. The AMS is operated in two modes: (1) a continuous mass spectrum 
(MS) mode, which produces mass concentrations of non-refractory species without size information; and (2) a particle time-of-flight (P-TOF) size distribution measurement mode for selected $\mathrm{m} / \mathrm{z}$ settings of the quadrupole (Jimenez et al., 2003). The AMS alternated between the P-TOF and MS modes approximately every $25 \mathrm{~s}$ during this study. The method detection limits of $\mathrm{NO}_{3}^{-}, \mathrm{SO}_{4}^{2-}, \mathrm{NH}_{4}^{+}$, and organics are estimated to be $0.01,0.05,0.11$, and $0.15 \mu \mathrm{g} \mathrm{m}^{-3}$, for a $10 \mathrm{~min}$ averaging time, respectively, based on sampling particle free ambient air (filtered by a HEPA filter) (Zhang et al., 2004a). The standard errors of the other reported parameters, such as concentration factors and artifacts, were calculated through error propagation. Detailed information on AMS operation and data analysis is described in a separate paper (Zhang et al., 2004a).

\subsection{Experimental set-up}

The VACES-AMS measurements were carried out on 10, 18, and 19 September 2002 at the central monitoring site of the Pittsburgh Air Quality Study (Wittig et al., 2004). The site was located in an urban park, approximately $6 \mathrm{~km}$ from the downtown Pittsburgh. Roughly $1 \mathrm{~km}$ of parkland exists between the site and the residential areas in the predominant upwind direction (south and west). The site was several hundred meters from any major sources.

The performance of the concentrator was assessed by performing several back-to-back tests during which the AMS was alternately used with and without the concentrator at its inlet. On September 10 and 18, 2002, three back-to-back runs were made and on September 19, 2002 two runs were made. Each run was about 20-40 min, half with the concentrator and half without it. The integrated concentrations of sulfate, nitrate, ammonium and organics, as well as their size distributions during the part of the runs with the concentrator were compared with those during the part of the runs without the concentrator.

When the AMS was sampling behind the concentrator, its sampling inlet was connected to the minor flow of the virtual impactor via a silica-gel diffusion drier. The sampling flow of the AMS was the nominal $0.0851 \mathrm{~min}^{-1}$, the rest of the minor follow $\left(\sim 4.91 \mathrm{~min}^{-1}\right)$ was drawn by a separate vacuum pump. The concentration factor of the VACES was monitored regularly by attaching a TSI CPC 3022 particle counter to the minor flow of the concentrator and comparing the counts with the counts without the concentrator.

In parallel to the measurements with the AMS, the ambient aerosol size distributions in the size range from $10 \mathrm{~nm}$ to $2.5 \mu \mathrm{m}$ in diameter were continuously monitored with two TSI SMPS systems (TSI 3936N25 and TSI 3936L10, TSI Inc.) and an APS system (TSI 3320, TSI Inc.).

\section{Results and discussion}

\subsection{Effect of concentrator on semi-volatile aerosol material}

The concentrations of PM sulfate, nitrate, ammonium, and organics measured during the experiments, as well as the corresponding concentration factors are given in Table 1. During the first 2 days the concentration factors for sulfate and ammonium were about 2 times lower than the concentration factor calculated from the ratio of the inlet and minor flows of the virtual impactor. The measured concentration factors were verified with the CPC measurements that gave the same concentration factor as the AMS sulfate. The flows were also checked regularly and were correct. Thus, the reason for this discrepancy is 
Table 1

Average concentrations and standard deviations in $\mu \mathrm{g} / \mathrm{m}^{3}$ of the measured aerosol components and the corresponding concentration factors

\begin{tabular}{|c|c|c|c|c|c|c|c|c|c|c|c|c|}
\hline \multirow[t]{2}{*}{ Date } & \multicolumn{3}{|l|}{ Sulfate } & \multicolumn{3}{|c|}{ Ammonium } & \multicolumn{3}{|l|}{ Nitrate } & \multicolumn{3}{|l|}{ Organics } \\
\hline & $\mathrm{OFF}^{\mathrm{a}}$ & $\mathrm{ON}^{\mathrm{b}}$ & $\mathrm{F}^{\mathrm{c}}$ & OFF & $\mathrm{ON}$ & $\mathrm{F}$ & OFF & $\mathrm{ON}$ & $\mathrm{F}$ & OFF & $\mathrm{ON}$ & $\mathrm{F}$ \\
\hline $10 / 9 / 02$ & $19.3 \pm 0.9$ & $201 \pm 3.1$ & $10.4 \pm 0.5$ & $4.8 \pm 0.5$ & $61.3 \pm 1.7$ & $12.7 \pm 1.3$ & $0.4 \pm 0.1$ & $10.0 \pm 0.3$ & $24.1 \pm 3.3$ & $5.8 \pm 0.2$ & $60.5 \pm 0.7$ & $10.4 \pm 0.4$ \\
\hline $18 / 9 / 02$ & $21.3 \pm 1.0$ & $278 \pm 3.6$ & $13.1 \pm 0.6$ & $7.3 \pm 0.6$ & $95.3 \pm 2.1$ & $13.0 \pm 1.1$ & $0.6 \pm 0.1$ & $21.3 \pm 0.4$ & $33.9 \pm 3.8$ & $7.6 \pm 0.2$ & $122 \pm 1.0$ & $16.1 \pm 0.5$ \\
\hline $19 / 9 / 02$ & $6.6 \pm 0.6$ & $143 \pm 2.6$ & $21.8 \pm 1.9$ & $2.4 \pm 0.3$ & $50.7 \pm 1.5$ & $21.5 \pm 3.1$ & $0.2 \pm 0.0$ & $5.2 \pm 0.2$ & $26.4 \pm 5.3$ & $2.9 \pm 0.1$ & $68.9 \pm 0.7$ & $24.0 \pm 1.3$ \\
\hline
\end{tabular}

${ }^{\mathrm{a}} \mathrm{OFF}$ : when the concentrator was off.

${ }^{\mathrm{b}} \mathrm{ON}$ : when the concentrator was on.

${ }^{\mathrm{c}} \mathrm{F}$ : the concentration factor.

unknown. The agreement between the AMS and the CPC also indicates that there was no change in the particle collection efficiency of the AMS (Alfarra et al., 2004; Allan et al., 2003) between the ambient and concentrated aerosol experiments, which would be expected given the relatively low ambient relative humidities (25-58\%) and the similar RH expected after the concentration and the diffusion dryer.

The concentrator factors for sulfate during each of the experiments were used as the reference for other measured components. This was done for the following reasons: (1) sulfate is a stable aerosol component with least likely gaseous artifacts, due to the very low vapor pressure of sulfuric acid, and to the very short time the air spends in the concentrator $(0.2 \mathrm{~s})$ for $\mathrm{SO}_{2}$-to-sulfate conversion via aqueous chemistry to be significant (maximum formation was estimated to be of the order of $1 \mathrm{ng} / \mathrm{m}^{3}$ ); (2) The CPC and the AMS sulfate measurements showed virtually the same enhancement factor. The CPC counts are mostly determined by particles smaller than $100 \mathrm{~nm}$ and the AMS measurements (of aerosol species mass) are mostly determined by particles larger than $100 \mathrm{~nm}$. The fact that the enhancement factors measured with these two different instruments agreed is an indication that the deviation from the theoretical enhancement efficiency (based on the VACES flows) is not due to changes in the AMS collection efficiency. The AMS can have lower than unity particle collection efficiency mainly due to particle bounce at the vaporizer (Allan et al., 2004; T. Onasch, Aerodyne Research, Personal Communication, 2004), which can be a function of particle composition and water content. Given that concentrated particles were equilibrated back to ambient conditions after the concentrator and before AMS analysis and that the observed condensation of additional material is very small, we believe that the AMS collection efficiency stays essentially the same during each experiment.

On 18/9/02 and 19/9/02 the concentration factors for nitrate, organics, and ammonium were about two times higher than those of sulfate, indicating that some extra particulate material had been formed in the concentrator. The size distributions of organics and especially nitrate on these 2 days were distorted after the concentrator (Fig. 1). Note that the original mode of nitrate mass size distribution changes approximately by the factor close to that of sulfate, while the increase in mass is due to the appearance of the second mode at smaller sizes. This change in the size distributions is another indication that an extra amount of nitrate, ammonia and organics was formed in the concentrator.

The amount of the extra material (artifact) was calculated using the following formula:

$$
\Delta C=\frac{C-C_{\mathrm{a}} X}{X}
$$



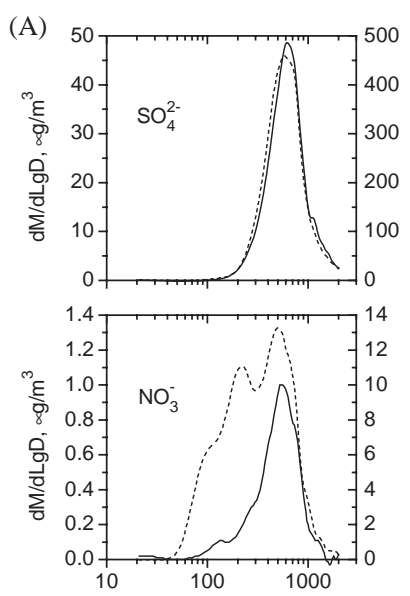

Vacuum aerodynamic diameter, $\mathrm{nm}$
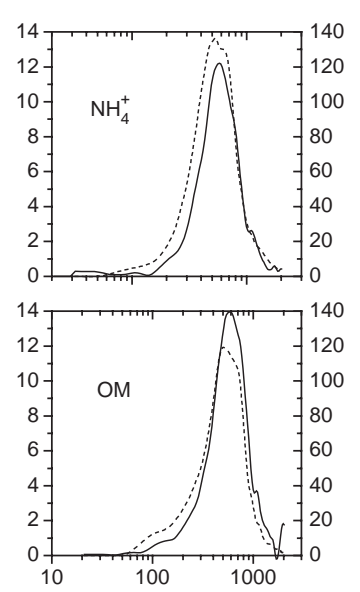

Vacuum aerodynamic diameter, $\mathrm{nm}$
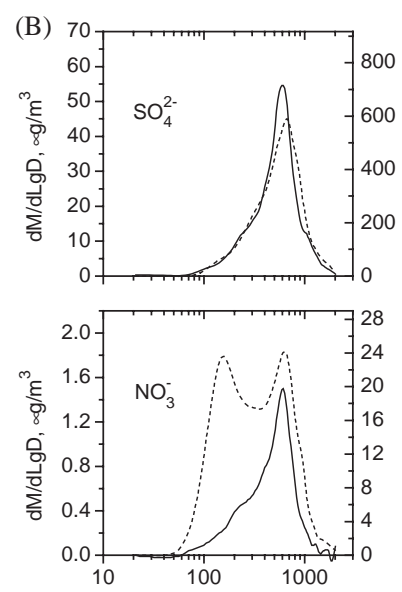

Vacuum aerodynamic diameter, $\mathrm{nm}$
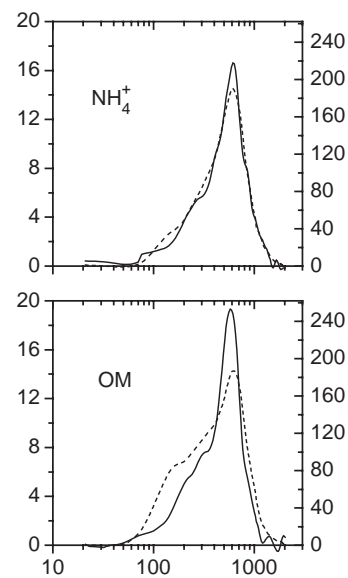

Vacuum aerodynamic diameter, $\mathrm{nm}$
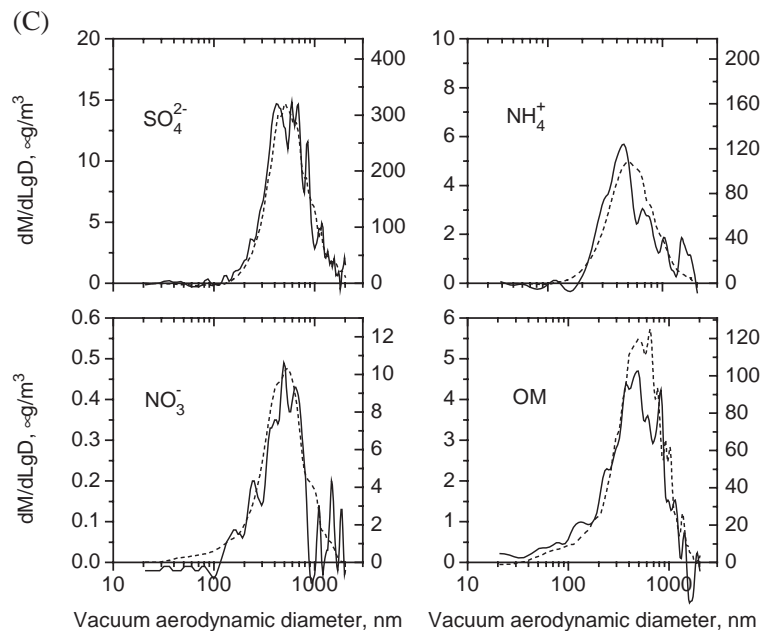

Fig. 1. Size distributions of sulfate, ammonium, nitrate, and organics measured without and with the VACES concentrator (solid and broken lines, respectively). Measurements with the concentrator are plotted using the right-hand axes, which were scaled by the corresponding concentration factor of sulfate. Note the difference in scales for sulfate and nitrate. (A) September 10, 2002; (B) September 18, 2002; (C) September 19, 2002.

in which $\Delta C$ is the concentration of the substance that has formed in the concentrator; $C$ and $C_{\mathrm{a}}$ are the concentrations measured with and without the concentrator, respectively; $X$ is the actual (or true) concentration factor taken to be that of sulfate, which is the least likely subjected to the condensation artifacts.

The calculated artifacts are given in Table 2. The table also contains relative magnitude of the artifacts: relatively to the original concentration of the species as well as relatively to the total $\left(\mathrm{PM}_{2.5}\right)$ aerosol mass. It is clear that even though the relative magnitude of the artifact may be large, its absolute value is small. For example, for the 3 days of the study the average nitrate artifact was found to be $131 \%, 159 \%$, and $21 \%$ of the original nitrate concentration. However, the corresponding average absolute artifact concentrations 
Table 2

Average concentrations of the extra ammonium, nitrate and organics formed in the concentrator (see Eq. (1)), their fractions of the original and concentrated concentration of each of the species $\left(\mathrm{d} C / C_{\mathrm{a}}, \mathrm{d} C / C_{\mathrm{c}}\right.$, respectively), and their fractions of the total aerosol mass $(\mathrm{d} C / M)$. Standard deviations of each value are also given

\begin{tabular}{|c|c|c|c|c|c|c|c|c|c|c|c|c|}
\hline \multirow[t]{2}{*}{ Date } & \multicolumn{3}{|l|}{ Ammonium } & \multicolumn{3}{|c|}{ Nitrate } & \multicolumn{3}{|r|}{ Organics } & \multirow[b]{2}{*}{$\begin{array}{l}\mathrm{d} C / C_{\mathrm{a}} \\
(\%)\end{array}$} & \multirow[b]{2}{*}{$\begin{array}{l}\mathrm{d} C / C_{\mathrm{c}} \\
(\%)\end{array}$} & \multirow[b]{2}{*}{$\begin{array}{l}\mathrm{d} C / M \\
(\%)\end{array}$} \\
\hline & $\begin{array}{l}\mathrm{d} C \\
\left(\mu \mathrm{g} / \mathrm{m}^{3}\right)\end{array}$ & $\begin{array}{l}\mathrm{d} C / C_{\mathrm{a}} \\
(\%)\end{array}$ & $\begin{array}{l}\mathrm{d} C / C_{\mathrm{c}} \\
(\%)\end{array}$ & $\begin{array}{l}\mathrm{d} C / M \\
(\%)\end{array}$ & $\begin{array}{l}\mathrm{d} C \\
\left(\mu \mathrm{g} / \mathrm{m}^{3}\right)\end{array}$ & $\begin{array}{l}\mathrm{d} C / C_{\mathrm{a}} \\
(\%)\end{array}$ & $\begin{array}{l}\mathrm{d} C / C_{\mathrm{c}} \\
(\%)\end{array}$ & $\begin{array}{l}\mathrm{d} C / M \\
(\%)\end{array}$ & $\begin{array}{l}\mathrm{d} C \\
\left(\mu \mathrm{g} / \mathrm{m}^{3}\right)\end{array}$ & & & \\
\hline $10 / 9 / 02$ & $1.05 \pm 0.6$ & $21.7 \pm 12.3$ & $1.7 \pm 0.6$ & $3.5 \pm 1.9$ & $0.55 \pm 0.1$ & $131 \pm 26$ & $5.5 \pm 1.0$ & $1.8 \pm 0.3$ & $-0.01 \pm 0.4$ & $-0.1 \pm 6.4$ & $0.0 \pm 0.7$ & $0.0 \pm 1.2$ \\
\hline $18 / 9 / 02$ & $-0.01 \pm 0.7$ & $-0.2 \pm 1.4$ & $0.0 \pm 0.7$ & $0.0 \pm 0.2$ & $1.0 \pm 0.1$ & $159 \pm 25$ & $4.7 \pm 0.5$ & $2.7 \pm 0.3$ & $1.75 \pm 0.5$ & $23.1 \pm 6.8$ & $1.4 \pm 0.4$ & $4.8 \pm 1.4$ \\
\hline $19 / 9 / 02$ & $-0.04 \pm 0.4$ & $-1.6 \pm 16$ & $-0.1 \pm 0.8$ & $-0.3 \pm 0.5$ & $0.04 \pm 0.0$ & $20.9 \pm 23$ & $0.8 \pm 0.0$ & $0.3 \pm 0.4$ & $0.29 \pm 0.3$ & $10.0 \pm 10.8$ & $0.4 \pm 0.4$ & $2.4 \pm 2.6$ \\
\hline
\end{tabular}

are $0.55,1.0$, and $0.04 \mu \mathrm{g} / \mathrm{m}^{3}$. Because of the low absolute values of the artifact, its contribution to the total aerosol mass is very small (less than $3 \%$ for nitrate).

\subsection{Partitioning of semi-volatile components during concentration}

The most probable reason for formation of the extra nitrate in the concentrator is a redistribution of nitric acid from the gas to the aerosol phase in the concentrator. Even though the aerosol is re-equilibrated to the original conditions (relative humidity and temperature) after the concentrator, some of the semivolatile material that was in the gas phase upstream of the concentrator may be left in the aerosol phase after the concentrator, as is explained in the following analysis. It should be kept in mind that this analysis assumes an "ideal" situation, i.e. the aerosol and the gas phase are in equilibrium at any time during the passage through the concentrator (i.e. there are no kinetic limitations for reaching equilibrium) and there are no losses of gaseous species or aerosol particles within the concentrator.

Let us assume that in the ambient air there is a semi-volatile substance that is in thermodynamic equilibrium with its solid (aerosol) phase at ambient temperature $\left(T_{\mathrm{a}}\right)$ and relative humidity $\left(\mathrm{RH}_{\mathrm{a}}\right)$. Let the concentration of the substance in the aerosol phase be $C_{\mathrm{a}}$ and its saturation concentration (vapor pressure) as a function of temperature and relative humidity is $C_{\text {sat }}(T, \mathrm{RH})$. Further, let the sample air in the condenser be at temperature $T_{\mathrm{c}}$ and relative humidity $\mathrm{RH}_{\mathrm{c}}$.

When the air is cooled in the condenser the saturation vapor pressure of the substance is decreased and some of the gas condenses on the particles. The amount of condensed material $\left(C_{\text {con }}\right)$ per unit volume of air is

$$
C_{\text {con }}=C_{\text {sat }}\left(T_{\mathrm{a}}, \mathrm{RH}_{\mathrm{a}}\right)-C_{\mathrm{sat}}\left(T_{\mathrm{c}}, \mathrm{RH}_{\mathrm{c}}\right)
$$

After the condenser the sample air passes through the virtual impactor, which is at conditions close to those of the condenser. The aerosol and some of the gas exit the impactor with the minor flow. Let the aerosol concentration in the minor flow be increased relatively to the inlet flow by a concentration factor $X$. In the minor flow, the concentration of species in the gas phase is $C_{\mathrm{sat}}\left(T_{\mathrm{c}}, \mathrm{RH}_{\mathrm{c}}\right)$ and the concentration in the aerosol is

$$
C_{\text {minor }}=\left(C_{\mathrm{a}}+C_{\mathrm{con}}\right) X \text {. }
$$


After the minor flow is re-equilibrated to the ambient temperature and dried to $\mathrm{RH}_{\mathrm{d}}$, some of the substance in the aerosol phase is evaporated. The amount of evaporated substance is

$$
C_{\text {evap }}=C_{\text {sat }}\left(T_{\mathrm{a}}, \mathrm{RH}_{\mathrm{d}}\right)-C_{\text {sat }}\left(T_{\mathrm{c}}, \mathrm{RH}_{\mathrm{c}}\right) .
$$

The concentration in the aerosol phase after re-equilibration is the concentration of the aerosol in the minor flow before re-equilibration minus the amount of evaporated material during the equilibration. Using Eqs. (2) and (3) into Eq. (4), the aerosol concentration after re-equilibration, i.e. the actual output from the concentrator is

$$
C_{\text {final }}=C_{\mathrm{a}} X+\Delta C_{\mathrm{a}}
$$

in which $\Delta C_{\mathrm{a}}$ is the amount of extra substance that was formed in the aerosol phase by passage through the concentrator:

$$
\Delta C_{\mathrm{a}}=\left(C_{\mathrm{sat}}\left(T_{\mathrm{a}}, \mathrm{RH}_{\mathrm{a}}\right)-C_{\mathrm{sat}}\left(T_{\mathrm{c}}, \mathrm{RH}_{\mathrm{c}}\right)\right) X-C_{\mathrm{sat}}\left(T_{\mathrm{a}}, \mathrm{RH}_{\mathrm{d}}\right)+C_{\mathrm{sat}}\left(T_{\mathrm{c}}, \mathrm{RH}_{\mathrm{c}}\right),
$$

which, in turn, can be approximated by neglecting the difference in $C_{\text {sat }}\left(T_{\mathrm{a}}, \mathrm{RH}_{\mathrm{a}}\right)$ and $C_{\mathrm{sat}}\left(T_{\mathrm{a}}, \mathrm{RH}_{\mathrm{d}}\right)$ :

$$
\Delta C_{\mathrm{a}}=\left(C_{\mathrm{sat}}\left(T_{\mathrm{a}}, \mathrm{RH}_{\mathrm{a}}\right)-C_{\mathrm{sat}}\left(T_{\mathrm{c}}, \mathrm{RH}_{\mathrm{c}}\right)\right)(X-1) .
$$

The amount of extra aerosol species that is formed in the concentrator is, thus, proportional to the difference in the saturation concentration (vapor pressure) of the species at the conditions of the ambient air and inside the condenser.

The apparent concentration factor (the ratio of the aerosol concentration after the concentrator to the aerosol concentration in the ambient air) is then:

$$
X_{\mathrm{a}}=X+(X-1) \frac{\Delta C_{\mathrm{sat}}}{C_{\mathrm{a}}}
$$

in which $\Delta C_{\text {sat }}$ is the difference in the saturation concentration (vapor pressure) of the species at the conditions of the ambient air and inside the condenser.

A better measure of the formation of extra material is the relative error in the concentration factor:

$$
E_{\mathrm{x}}=\frac{X_{\mathrm{a}}-X}{X}=\left(1-\frac{1}{X}\right) \frac{\Delta C_{\mathrm{sat}}}{C_{\mathrm{a}}} .
$$

In our analysis so far we have neglected the effect of the humidifier. The humidifier has no effect on the output aerosol concentration because the process is reversible (the system is closed during transit from the humidifier to the condenser, while after the separation in the virtual impactor it is not).

From Eq. (9) it follows, that the relative error in the concentration factor is higher at higher concentration factors and at lower aerosol ambient concentrations. It is also proportional to $\Delta C_{\text {sat }}$. According to the Clausius-Clapeyron equation, substances that have a larger enthalpy of vaporization will have a larger $\Delta C_{\text {sat }}$ and thus exhibit larger errors. It should be noted that an aerosol species can be formed even if its gaseous concentration is lower than the saturation pressure at ambient conditions, but is higher than the saturation pressure at the conditions in the condenser.

$\Delta C_{\text {sat }}$, and, thus, the relative error in the concentration factor (Eq. (9)), also depends on the difference in temperatures between the ambient air and the air inside the condenser. The VACES concentrator was designed in such a way that the air in the condenser is at $20^{\circ} \mathrm{C}$. This prevents much of a temperature 
difference between the condenser and the sample air, especially if it is equilibrated to room temperature, which is often the case, especially in the human and animal exposure studies. Thus, most of the potential artifact formation for species, which vapor pressure does not depend on relative humidity, is avoided. If the sample air temperature differs from $20^{\circ} \mathrm{C}$, artifact formation according to Eq. (8) may be expected. In that case it is recommended that the temperature setting of VACES be adjusted such that the temperature of the air in the condenser is equal to the ambient temperature.

$\Delta C_{\text {sat }}$, also depends on the relative humidity, especially for water-soluble species. For example, ammonium nitrate has a negligible vapor pressure at $100 \% \mathrm{RH}$, the conditions of the air in the condenser. In this case all of the gas phase will be condensed onto the particles in the condenser (assuming no losses) and the formation of extra material would be proportional to the amount of the substance in the gas phase at ambient conditions. Thus, the effect of the concentrator on water-soluble species is expected to be stronger than that for water-insoluble substances. This agrees with our observations that show a larger change in nitrate mass in comparison to that of organics, which are often not or less hygroscopic and which vapor pressure is not expected to depend strongly on RH. It should be noted that organics partition to the aerosol before their saturation vapor pressure is reached by adsorption and absorption, depending on the amount and properties of the pre-existing aerosol organic phase. For a more rigorous treatment of organic artifacts, the analysis here would need to be modified using the formulation of Pankow (1994).

The observations of the increased nitrate mass in the concentrator were used to calculate the amount of the gas that has condensed onto the particles in the concentrator using the following formula, which follows from Eq. (8):

$$
\Delta C_{\mathrm{NO}_{3}}=\frac{C_{\text {final }}-C_{\mathrm{a}} X}{X-1}
$$

in which $\Delta C_{\mathrm{NO}_{3}}$ is the concentration of nitrate that has condensed onto particles in the condenser; $C_{\text {final }}$ and $C_{\mathrm{a}}$ are the concentrations of nitrate measured with and without the concentrator, respectively; $X$ is the actual (or true) concentration factor taken to be that of sulfate, which is the species least likely subjected to condensation artifacts. It should be noted that the amount of the condensed gas is larger than the observed artifact mass (Eq. (1)), because a part of the condensed gas has re-evaporated after the aerosol was equilibrated after exiting the condenser.

During the experiments on September 10, 18 and 19 on average $0.6,1.1$ and less than $0.1 \mu \mathrm{g} / \mathrm{m}^{3}$ of nitrate, respectively, has condensed to the aerosol in the concentrator (Table 1). The difference between the first 2 days and the last one was mostly in the air pollution conditions, with the former two being more polluted than the latter. The $\mathrm{PM}_{2.5}$ sulfate concentration on 10 and 18 September was 19 and $21 \mu \mathrm{g} / \mathrm{m}^{3}$, respectively. On 19 September the concentration decreased to $6.6 \mu \mathrm{g} / \mathrm{m}^{3}$. Therefore, the virtual absence of extra nitrate formation on 19 September is probably due to limited availability of nitric acid.

It should be also noted that the condensed amounts on 10 and 18 September are relatively low in comparison to the maximum possible under the conditions of the experiments. Unfortunately, no measurements of nitric acid or ammonia are available for this period to perform a direct comparison. However, under similar conditions nitric acid concentrations of $5-10 \mu \mathrm{g} / \mathrm{m}^{3}$ were measured in Pittsburgh a year prior to this study. If there are no losses of the gas-phase components in the VACES, practically all of the available nitric acid should have been condensed to the particles. In fact, only a small fraction (about $10 \%$ ) of the estimated nitric acid concentration has condensed on the particles. This is most probably due to the losses of gas-phase nitric acid which is stripped by water in the saturator of the VACES as well as other wall losses. 


\subsection{Size dependence of the artifact}

Fig. 1 shows size distributions of the measured chemical species during the three experiments. The size distributions during the VACES runs were scaled by the concentration factors of sulfate for each of the runs. The size distributions of sulfate are preserved after the passage through the concentrator, while that of nitrate, and to a lesser degree those of ammonium and organics, are not, except for the run of 19 September. The striking feature on 10 and 18 September is the increase of nitrate concentration at small sizes, in the size range of 100-200 nm. Similarly, on these days the enhancement factor for the integrated sulfate concentration is smaller than the factor for nitrate (Table 1). The change of size distribution of nitrate, together with its concentration factor that is higher than that of sulfate, suggests formation of nitrate in VACES on 10 and 18 September. The changes in the size distributions of nitrate on September 10 and 18 are far larger than the uncertainties of the AMS measurement.

As Fig. 1 shows, the extra nitrate (as well as some organics) was mostly formed at small sizes (smaller than about $300 \mathrm{~nm}$ ), while the shape of the distribution was mostly preserved at and around the mode of the mass distribution (500-700 nm). The probable reason for such behavior is the shape of the size distribution of the aerosol surface area. Condensation of the gas-phase species will proceed mostly to the size range of maximum condensational sink, as described in Pirjola et al. (1999). The average size distributions of condensational sink of ambient aerosol during the experiments, as measured with the SMPS, are shown in Fig. 2. The maximum of the condensational sink distribution is located at sizes smaller than the mode of the volume (mass distribution), which explains why the extra nitrate was forming mostly at small sizes. However, the exact position of the extra nitrate on the size distribution will be controlled by the kinetics of nitrate condensation, which occurs simultaneously to water condensation. Because nitrate condenses during the droplet growth, which changes the aerosol surface distribution, the final result may only be determined by numerical calculations of condensational processes. Such calculations, however, are beyond the scope of this work.

\subsection{Modeling of artifact sensitivity to availability of ammonia and nitric acid}

We have used the GFEMN thermodynamic model (Ansari \& Pandis, 1999) to assess the effect of ammonia and nitric acid availability on the error in the concentration factor for nitrate aerosol. The aerosol was assumed to contain either 10 or $20 \mu \mathrm{g} / \mathrm{m}^{3}$ of sulfate, while concentrations of total available ammonia and nitric acid were varied. For these simulations the ambient temperature was set to $20^{\circ} \mathrm{C}$ and relative humidity to $50 \%$. Based on our observations (see above) we assumed that $90 \%$ of the gas-phase ammonia and nitric acid were lost in the humidifier and the remaining $10 \%$ of the gases condensed onto the particles prior to their entrance into the virtual impactor. The concentration of the aerosol was then increased by the concentration factor, which was taken to be 20 . After that the model "equilibrated" the concentrated aerosol to the conditions found after the VACES $\left(20^{\circ} \mathrm{C}\right.$ and $\left.35 \% \mathrm{RH}\right)$.

The ratio of the predicted concentration factor for nitrate to the theoretical concentration factor (set to be 20) as a function of the total available ammonia and nitric acid is shown in Fig. 3. The modeling results indicate that the error is higher in ammonia-limited conditions, while in ammonia-rich environment the modeled factor approaches the theoretical one. It should be noted that the high increase in the concentration factor at low ammonia concentrations is due to the low initial aerosol nitrate concentrations at those conditions. The absolute artifact in the aerosol nitrate after the concentrator as determined by Eq. (1) is shown in Fig. 4. 


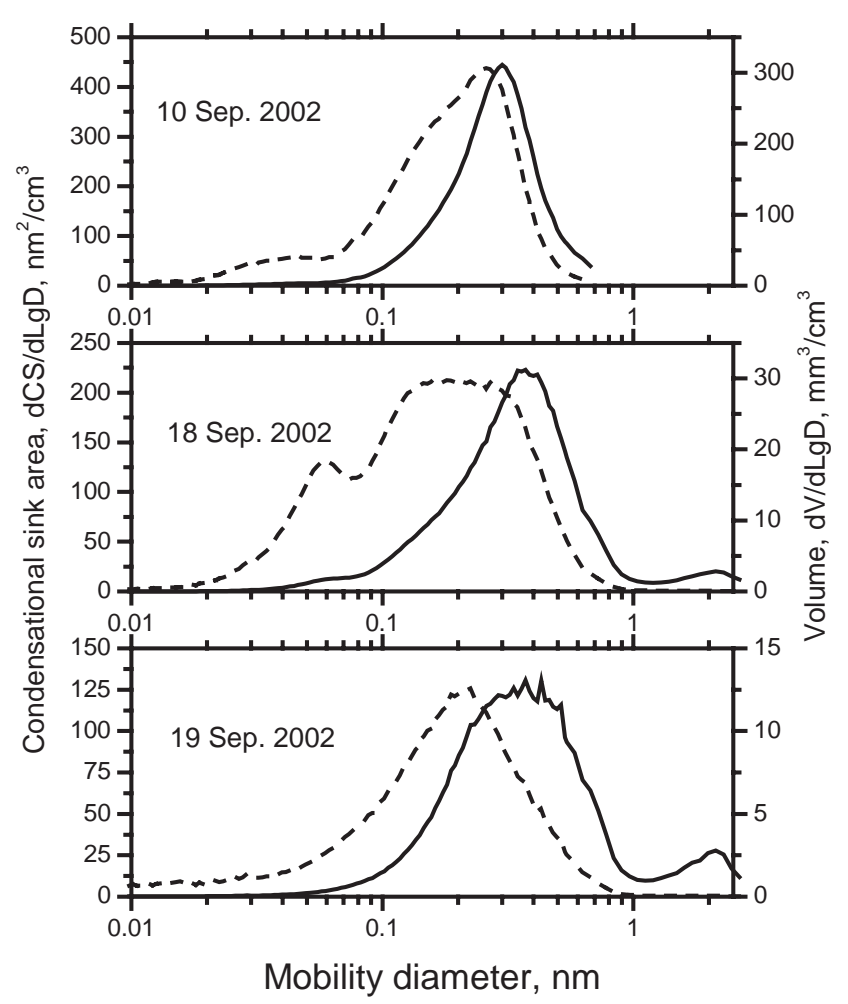

Fig. 2. Volume (solid lines) and condensational sink (broken lines) size distributions measured with the SMPS.

Our observations support the trend predicted by the model. In our experiments the artifact was observed on 10 and 18 September, when the measured $\mathrm{NH}_{4}^{+}$mass concentrations were approximately $10-30 \%$ in deficit to fully neutralize the measured $\mathrm{NO}_{3}^{-}$and $\mathrm{SO}_{4}^{2-}$, indicating ammonia-limited conditions. On September 19, when no discernable artifact was observed, the aerosol was neutral, indicating that the conditions were not ammonia-limited. The sensitivity of the artifact to availability of ammonia is probably also the reason why no artifact was observed in the previous tests which were carried out either in California in ammonia-rich conditions (Geller et al., 2002; Kim et al., 2001b; Misra et al., 2004) or in Pittsburgh in March (Zhao et al., 2004) when the aerosol was neutral.

\subsection{Recommendations}

Given the potential of artifact formation in the concentrators using water-condensation technology it is recommended to use a denuder to remove interfering species from the air stream prior to its entrance into the humidifier. This, however, may lead to particle losses in the ultra-fine size range. Even though no artifact formation was observed on the cleanest day of the study (19 September), care should be taken when using VACES for nucleation and new particle growth studies, since even a small artifact can be large compared to the very small mass of these particles. For the exposure studies we would recommend to monitor concentration of species before and after the concentrator such that concentration factors for each 


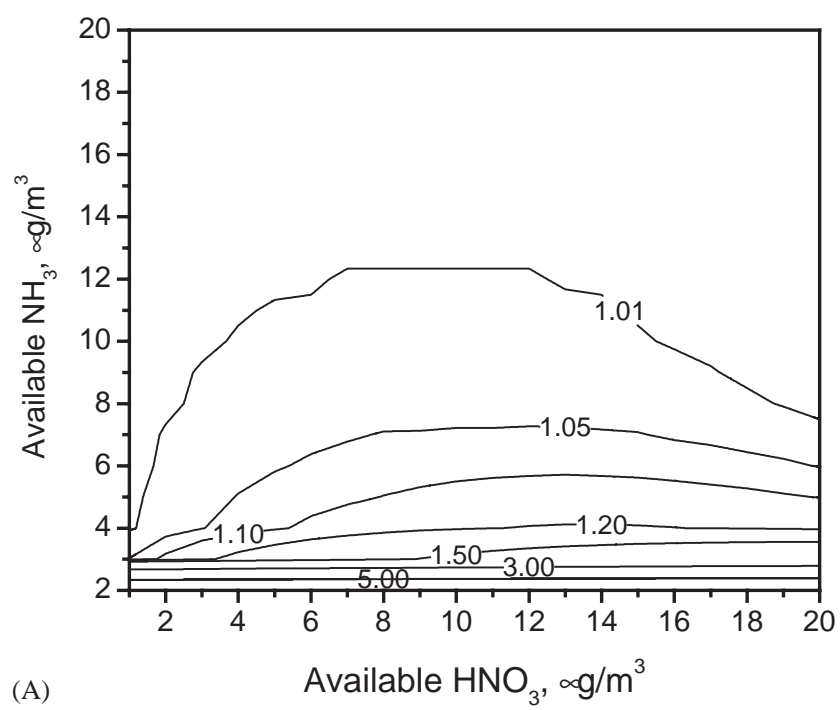

(A)

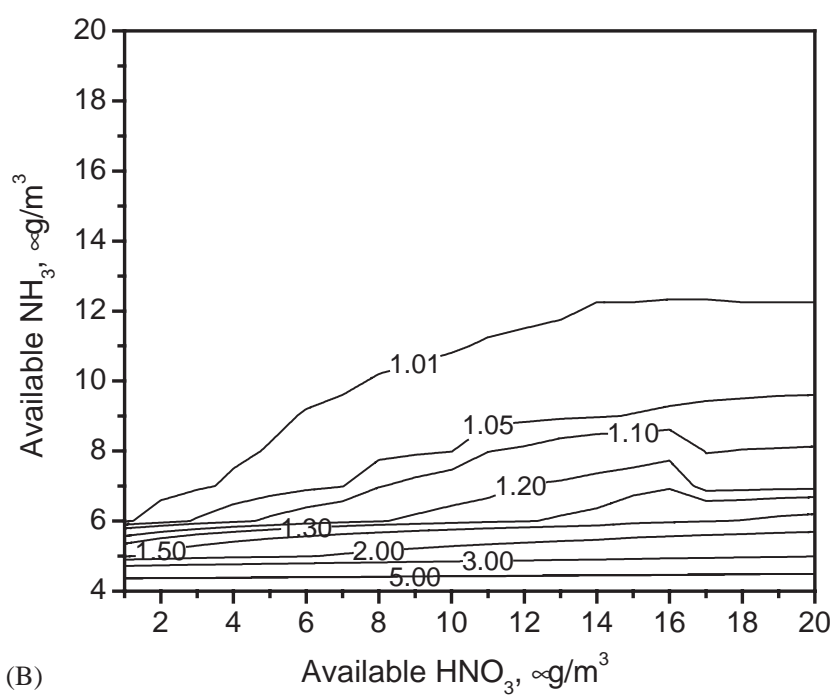

Fig. 3. Modeled increase in the concentration factor for aerosol nitrate relatively to the theoretical concentration factor at different amounts of available ammonia and nitric acid. (A) sulfate concentration is $10 \mu \mathrm{g} / \mathrm{m}^{3}$; (B) sulfate concentration is $20 \mu \mathrm{g} / \mathrm{m}^{3}$.

compound are known. These individual concentration factors can be then used to assess health effects (or lack thereof) of each compound. We would also like to reiterate, that the observed artifact formation is small in comparison to the total mass concentration of the concentrated aerosol.

\section{Summary and conclusions}

The effect of water condensation on semi-volatile aerosol species during their passage through a particle concentrator was assessed using the VACES concentrator coupled to the Aerodyne Aerosol Mass 

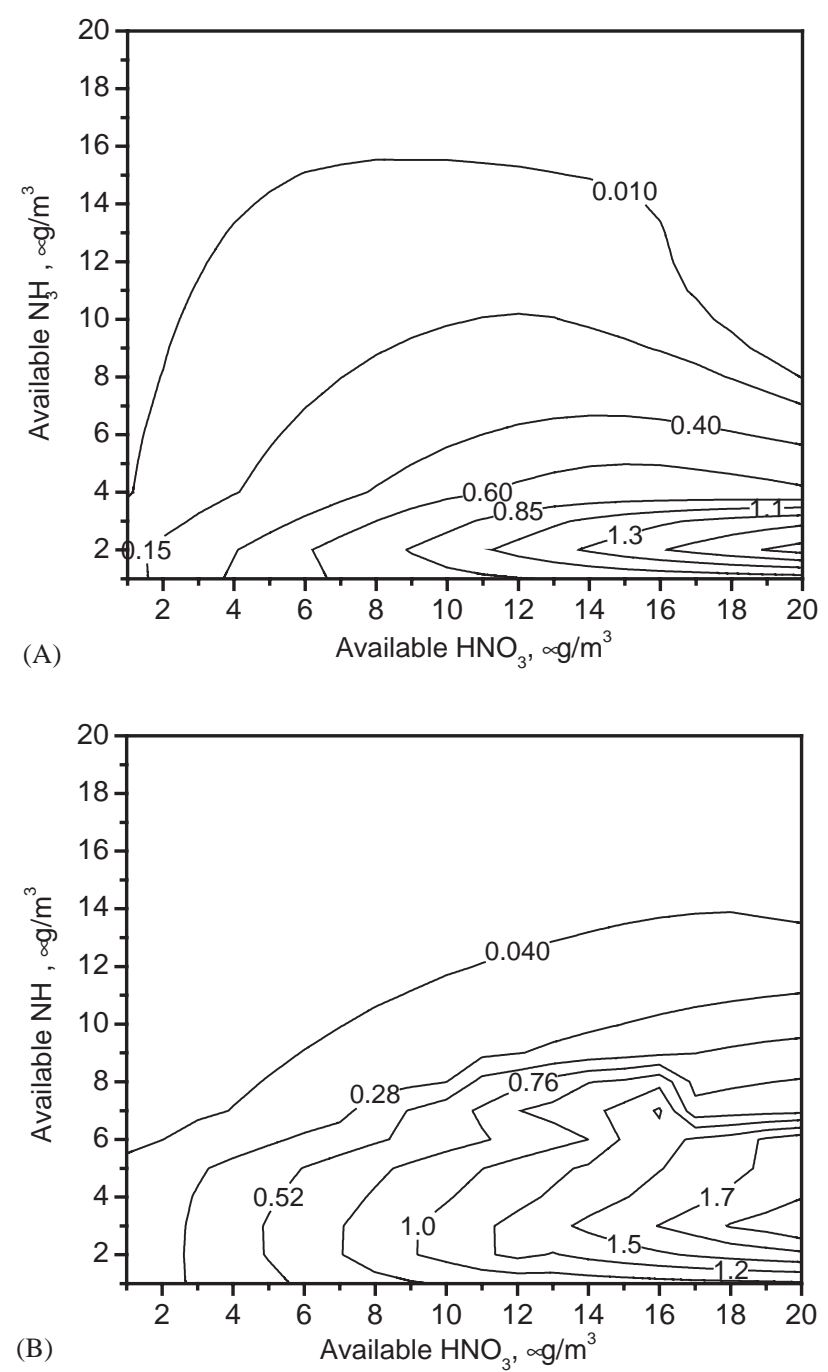

Fig. 4. Modeled increase in the concentration aerosol nitrate $\left(\mu \mathrm{g} / \mathrm{m}^{3}\right)$ due to the artifact after the concentrator at different amounts of available ammonia and nitric acid. (A) sulfate concentration is $10 \mu \mathrm{g} / \mathrm{m}^{3}$; (B) sulfate concentration is $20 \mu \mathrm{g} / \mathrm{m}^{3}$.

Spectrometer during measurements of ambient aerosol, with the following conclusions:

- The size distribution of sulfate is preserved after passage through the concentrator at all conditions encountered during the study. The concentration factors determined for sulfate mass do not always equal the theoretical concentration factors, but are very close to those simultaneously determined for total particle number using a CPC.

- The size distributions of ammonium, organics and nitrate are preserved at relatively clean conditions (sulfate concentrations around $7 \mu \mathrm{g} / \mathrm{m}^{3}$ ), while under more polluted conditions (sulfate concentrations around $20 \mu \mathrm{g} / \mathrm{m}^{3}$ ) they exhibit an increase at small sizes (50-300 $\mathrm{nm}$ in vacuum aerodynamic diameter). Such an increase is especially pronounced for nitrate. 
- The increase of nitrate and organic concentrations at small sizes after the passage through the concentrator corresponds to the sizes of maximum aerosol surface area and fastest gas-to-particle transfer.

- The absolute increase in concentration of nitrate observed in this study is rather small, of the order of $1 \mu \mathrm{g} / \mathrm{m}^{3}$ or less (i.e., $0.3-2.7 \%$ of the total aerosol mass concentration) and can be neglected for many practical purposes.

- An analysis of thermodynamic processes in the concentrator indicates that the formation of extra material in the concentrator is likely due to redistribution of the gas-phase material to the aerosol phase. The modeling indicates that nitrate artifact will be most pronounced in ammonia-limited conditions, while in ammonia-rich environment it becomes negligible.

- Even though the extent of the artifact is limited, to avoid its formation completely it is recommended to operate VACES with a denuder and/or with its condenser temperature set equal to the ambient temperature. If no denuder is used, we recommend that concentration of individual compounds be measured both before and after concentrator, such that concentration factors for individual species are known.

\section{Acknowledgements}

This research was conducted as part of the Pittsburgh Air Quality Study, which was supported by US Environmental Protection Agency under Contract R82806101 and the US Department of Energy National Energy Technology Laboratory under Contract DE-FC26-01NT41017. Q. Zhang and J.L. Jimenez's participation in this study was sponsored by the University of Colorado (J.L. Jimenez's startup funds). This work was additionally supported by the Southern California Particle Center and Supersite (SCPCS), funded by the US EPA (STAR award \#R82735201) and the California Air Resources Board (ARB; Grant \# 98-316). This manuscript has not been subjected to the EPA and ARB's peer and policy review, and therefore does not necessarily reflect the views of the Agencies. No official endorsement should be inferred.

\section{References}

Alfarra, M. R., Coe, H., Allan, J. D., Bower, K. N., Boudries, H., Canagaratna, M. R., Jimenez, J. L., Jayne, J. T., Garforth, A., Li, S. M., \& Worsnop, D. R. (2004). Characterization of urban and regional organic aerosols in the lower Fraser Valley using two aerodyne aerosol mass spectrometers. Atmospheric Environment, 38, 5745-5758.

Allan, J. D., Bower, K. N., Coe, H., Boudries, H., Jayne, J. T., Canagaratna, M. R., Millet, D. B., Goldstein, A. H., Quinn, P. K., Weber, R. J., \& Worsnop, D. R. (2004). Submicron aerosol composition at Trinidad Head, CA during ITCT 2K2, its relationship with gas phase volatile organic carbon and assessment of instrument performance. Journal of Geophysical Research-Atmospheres, 109(D23) D23S24, doi: 10.1029/2003JD004208.

Allan, J. D., Jimenez, J. L., Williams, P. I., Alfarra, M. R., Bower, K. N., Jayne, J. T., Coe, H., \& Worsnop, D. R. (2003). Quantitative sampling using an aerodyne aerosol mass spectrometer: 1. Techniques of data interpretation and error analysis (vol 108, art no 4090, 2003). Journal of Geophysical Research-Atmospheres, 108(D9).

Ansari, A. S., \& Pandis, S. N. (1999). Prediction of multicomponent inorganic atmospheric aerosol behavior. Atmospheric Environment, 33(5), 745-757.

Eatough, D. J., Pang, Y. B., \& Eatough, N. L. (1999). Determination of PM2.5 sulfate and nitrate with a PC-BOSS designed for routine sampling for semi-volatile particulate matter. Journal of the Air \& Waste Management Association, 49, 69-75.

Geller, M. D., Kim, S., Misra, C., Sioutas, C., Olson, B. A., \& Marple, V. A. (2002). A methodology for measuring size-dependent chemical composition of ultrafine particles. Aerosol Science and Technology, 36(6), 748-762. 
Jayne, J. T., Leard, D. C., Zhang, X. F., Davidovits, P., Smith, K. A., Kolb, C. E., \& Worsnop, D. R. (2000). Development of an aerosol mass spectrometer for size and composition analysis of submicron particles. Aerosol Science and Technology, 33(1-2), 49-70.

Jimenez, J. L., Jayne, J. T., Shi, Q., Kolb, C. E., Worsnop, D. R., Yourshaw, I., Seinfeld, J. H., Flagan, R. C., Zhang, X. F., Smith, K. A., Morris, J. W., \& Davidovits, P. (2003). Ambient aerosol sampling using the aerodyne aerosol mass spectrometer. Journal of Geophysical Research-Atmospheres 108(D7).

Kim, S., Jaques, P. A., Chang, M. C., Barone, T., Xiong, C., Friedlander, S. K., \& Sioutas, C. (2001a). Versatile aerosol concentration enrichment system (VACES) for simultaneous in vivo and in vitro evaluation of toxic effects of ultrafine, fine and coarse ambient particles-Part II: field evaluation. Journal of Aerosol Science, 32(11), 1299-1314.

Kim, S., Jaques, P. A., Chang, M. C., Froines, J. R., \& Sioutas, C. (2001b). Versatile aerosol concentration enrichment system (VACES) for simultaneous in vivo and in vitro evaluation of toxic effects of ultrafine, fine and coarse ambient particles-Part I: development and laboratory characterization. Journal of Aerosol Science, 32(11), 1281-1297.

Misra, C., Fine, P. M., Singh, M., \& Sioutas, C. (2004). Development and evaluation of a compact facility for exposing humans to concentrated ambient ultrafine particles. Aerosol Science and Technology, 38(1), 27-35.

Pankow, J. F. (1994). An absorption-model of gas-particle partitioning of organic-compounds in the atmosphere. Atmospheric Environment, 28(2), 185-188.

Peters, A., Dockery, D. W., Heinrich, J., \& Wichmann, H. E. (1997). Short-term effects of particulate air pollution on respiratory morbidity in asthmatic children. European Respiratory Journal, 10(4), 872-879.

Pirjola, L., Kulmala, M., Wilck, M., Bischoff, A., Stratmann, F., \& Otto, E. (1999). Formation of sulfuric acid aerosols and cloud condensation nuclei: an expression for significant nucleation and model comparison. Journal of Aerosol Science, $30(8), 1079$ $-1094$.

Pope, C. A., Dockery, D. W., \& Schwartz, J. (1995). Review of epidemiological evidence of health-effects of particulate airpollution. Inhalation Toxicology, 7(1), 1-18.

Sioutas, C., Kim, S., \& Chang, M. (1999). Development and evaluation of a prototype ultrafine particle concentrator. Journal of Aerosol Science, 30(8), 1001-1017.

Thurston, G. D., Ito, K., Hayes, C. G., Bates, D. V., \& Lippmann, M. (1994). Respiratory hospital admissions and summertime haze air-pollution in Toronto, Ontario-consideration of the role of acid aerosols. Environmental Research, 65(2), 271-290.

Willeke, K., \& Baron, P. A. (1993). Aerosol measurement: principles, techniques, and applications. New York: Van Nostrand Reinhold.

Wittig, A. E., Anderson, N., Khlystov, A. Y., Pandis, S. N., Davidson, C., \& Robinson, A. L. (2004). Pittsburgh Air Quality Study overview and preliminary scientific findings. Atmospheric Environment, 38, 3107-3125.

Zhang, Q., Canagaratna, M. C., Jayne, J. T., Worsnop, D. R., \& Jimenez, J. L. (2004a). Size-Resolved chemical composition and temporal variation of submicron particles in Pittsburgh-implications on aerosol sources and processes. Journal of Geophysical Research-Atmospheres, in press.

Zhang, Q., Stanier, C. O., Canagaratna, M. C., Jayne, J. T., Worsnop, D. R., Pandis, S. N., \& Jimenez, J. L. (2004b). Insights into the chemistry of nucleation bursts and new particle growth events in Pittsburgh based on aerosol mass spectrometry. Environmental Science and Technology, 38(18), 4797-4809.

Zhao, Y., Bein, K. J., Wexler, A. S., Misra, C., Fine, P. M., \& Sioutas, C. (2004). Using a particle concentrator to increase the hit rates of single particle mass spectrometers. Journal of Geophysical Research-Atmospheres, in press. 